\title{
Treatment of Parkinson's Disease with Trophic Factors
}

\author{
Amie L. Peterson and John G. Nutt \\ Parkinson's Disease Research, Educational and Clinical Center (PADRECC), Portland Veteran's Administration Medical \\ Center, and Department of Neurology, Oregon Health Sciences University, Portland, Oregon 97239
}

\begin{abstract}
Summary: Trophic factors are proteins that support and protect subpopulations of cells. A number have been reported to act on dopaminergic neurons in vitro and in vivo, making them potential therapeutic candidates for Parkinson's disease. All of these candidate factors protect dopaminergic neurons if given prior to, or with, selective neurotoxins. Fewer trophic factors, primarily glial-derived neurotrophic factor (GDNF) and its relative, neurturin (NRTN; also known as NTN), have been shown to restore function in damaged dopamine neurons after the acute effects of neurotoxins have subsided. A major barrier to clinical translation has been delivery. GDNF delivered by intracerebroventricular injection in patients was ineffective, probably because GDNF did not reach the target, the putamen, and intraputaminal infusion was ineffective, probably because of limited distribution within the puta-
\end{abstract}

men. A randomized clinical trial with gene therapy for NRTN is underway, in an attempt to overcome these problems with targeting and distribution. Other strategies are available to induce trophic effects in the CNS, but have not yet been the focus of human research. To date, clinical trials have focused on restoration of function (i.e., improvement of parkinsonism). Protection (i.e., slowing or halting disease progression and functional decline) might be a more robust effect of trophic agents. Laboratory research points to their effectiveness in protecting neurons and even restoring dopaminergic function after a monophasic neurotoxic insult. Utility for such compounds in patients with Parkinson's disease and ongoing loss of dopaminergic neurons remains to be proven. Key Words: Parkinson's disease, trophic factors, clinical trials, glial-derived neurotrophic factors, neurturin.

\section{INTRODUCTION}

Trophic factors are proteins that are important for the survival and function of specific cellular subpopulations. The full potential of these molecules as therapeutic agents is illustrated by the successes of erythropoietin in the treatment of anemia. Erythropoietin is a $35 \mathrm{kDa}$ glycoprotein whose effects are mediated through the erythropoietin receptor, initiating a signaling cascade of events. This includes activation of tyrosine protein kinases and phosphorylation of intracellular proteins to enhance proliferation, differentiation, and maturation of erythroid precursors. The importance of erythropoietin is underscored not only by its ability to treat anemia related to renal disease, various cancers, and antiviral therapies, but also by the severe anemia that develops as a consequence of the formation of neutralizing antibodies against erythropoietin. ${ }^{1}$

Address correspondence and reprint requests to: J.G. Nutt, M.D., Department of Neurology, Oregon Health Sciences University, Portland, OR 97239. E-mail: nuttj@ohsu.edu.

\section{TROPHIC FACTORS IN THE CENTRAL NERVOUS SYSTEM}

Cohen et al. ${ }^{2}$ discovered the first trophic factor with an effect on nerve cells; nerve growth factor (NGF), in 1954, when they isolated it from mouse sarcomas. Subsequently, a large number of trophic factors and their receptors have been identified in the CNS, including trophic factors from the periphery, such as erythropoietin and its receptor. ${ }^{3}$ Because of the therapeutic potential of trophic factors for neurological disorders, research in this area has been growing rapidly. A Medline search for three major neurotrophic factors-NGF, brain-derived neurotrophic factor (BDNF) and glial-derived neurotrophic factor (GDNF) - brings up almost 12,000 articles published since 1996.

A portion of trophic factors in the CNS can be grouped into families based on homology of the trophic factors, receptors, and common transduction pathways. NGF is a member of the neurotrophin family. Other members of this family include: BDNF, neurotrophin 3 (NT-3) and neurotrophin 4/5 (NT-4/5). The neurotrophins are synthesized as large precursor proteins in the range of 30 to $35 \mathrm{kDa}$ and then are cleaved at highly conserved 
TABLE 1. Trophic Factors of Particular Relevance to Parkinson's Disease

\begin{tabular}{lcccc}
\hline Superfamily & Family & Neurotrophic Factor & \multicolumn{1}{c}{ Receptors } & Affinity \\
\hline TGF $\beta$ and Cysteine knot & GDNF family & GDNF & GFR $\alpha 1>$ GFR $\alpha 2$ & RET \\
& & NRTN & GFR $\alpha 2>$ GFR $\alpha 1$ & RET \\
& & ARTN & GFR $\alpha 3$ & RET \\
Cysteine knot & PSPN & GFR $\alpha 4$ & RET \\
& Neurotrophin family & NGF & TrkA & p75 \\
& & BDNF & TrkB & p75 \\
& & NT3 & TrkC TrkA \& TrkB & p75 \\
$?$ & NT4/NT5 & TrkB & p75 \\
& MANF family & MANF & & $?$ \\
\hline
\end{tabular}

$\mathrm{ARTN}=$ artemin $; \mathrm{CDNF}=$ conserved dopamine neurotrophic factor GDNF $=$ glial-derived neurotrophic factor; $\mathrm{MANF}=$ mesencephalic astrocyte-derived neurotrophic factor; NGF $=$ nerve growth factor; NT $=$ neurotrophin; PSPN $=$ persephin; TGF $=$ transforming growth factor; Trk = tyrosine kinase receptor; ? = unknown.

regions to generate the mature protein. The mature proteins have roughly $50 \%$ homology, with similar numbers of amino acids (118-120) and molecular weights $(\sim 12 \mathrm{kDa})$. The mature proteins all form dimers and possess six cysteine residues in highly conserved positions that form three intrachain sulfide bonds. The variable domains determine the binding affinity of each member for a two-component receptor complex: the Trk family of tyrosine kinase receptors and p75, a tumor necrosis factor receptor (Table 1). ${ }^{4}$

The transforming growth factor beta (TGF $\beta$ ) superfamily is a trophic factor family with major relevance for Parkinson's disease (PD). It includes GDNF, neurturin, TGF $\beta$ types 1, 2, and 3, artemin, neublastin, enovin, and persephin. ${ }^{5,6}$ Similarly to the neurotrophin family, the TGF $\beta$ trophic factors also are synthesized as precursor proteins, which are cleaved into mature proteins with seven conserved cysteine residues that form dimers. There is more heterogeneity among members of the TGF $\beta$ superfamily, however, with GDNF having less than $20 \%$ homology with some of the other members of the family. ${ }^{7}$

Because of this, GDNF is often considered in its own family, along with neurturin, artemin, and persephin. Similarly to the neurotrophin family, the GDNF family interacts with a two-component receptor complex: GDNF family receptor alpha (GFR $\alpha$ ), which is a glucosylphosphoinositol-linked surface receptor, and RET, a receptor tyrosine kinase. The four members of the GDNF family have different receptors (GFR $\alpha$ types $1-4)$ but the specificity for the receptors is not exclusive; for example, neurturin can act through the GDNF receptor GFR $\alpha 1$, as well as through GFR $\alpha 2 .^{8}$

A new family of trophic factors with particular relevance to PD has been identified. This family currently has two members: mesencephalic astrocyte-derived neurotrophic factor (MANF) and conserved dopamine neurotrophic factor (CDNF). ${ }^{9,10}$ These trophic factors contain eight cysteine residues and are predicted to produce a unique folding structure. They represent a uniquely conserved protein family. ${ }^{10}$ The receptors for MANF and CDNF have not yet been described. The importance of these trophic factors is that MANF and CDNF appear to have more selective and potent effects on dopaminergic neurons than any other trophic factors currently known. ${ }^{9}$

Trophic factors in other families have trophic effects on the dopaminergic system, including basic fibroblast growth factor (bFGF), ciliary neurotrophic factor, epidermal growth factor, and insulin-like growth factor; these are reviewed elsewhere. ${ }^{11}$ Of these other factors, bFGF has received the most attention and has the most evidence to suggest that it could be effective in vivo. ${ }^{12}$

\section{MECHANISMS OF ACTION OF TROPHIC FACTORS}

In the late 1940s, Levi-Montalcini, Hamburger, and Cohen found that innervating neurons were lost after removal of peripheral target tissue. ${ }^{13}$ Based on this research, neurotrophic factors were thought to function primarily through a retrograde mechanism, with the basic tenants of the hypothesis being that 1) limited quantities of a neurotrophic factor are produced in a specific target tissue, 2) responsive neurons projecting to these targets compete for this limited quantity of trophic factor, 3 ) the factor is then bound to cell surface receptors, 4) receptors and trophic factor are internalized and 5) retrogradely transported to the neuronal cell nucleus, where they stimulate changes affecting neuronal survival and differentiation.

In the early studies it was found that axon terminals competed to form synapses with the target tissue, taking up NGF at nerve endings from the target and transporting the receptor-bound NGF to the cell body via retrograde transport. If adequate NGF was obtained from the target tissue, the connections were maintained and the neuron survived. Neurons unable to access adequate amounts of NGF, in contrast, atrophied and died. Green fluorescent 
protein has been used to visualize the movement of the NGF receptor, Trk, from the distal axon to the cell bodies after application NGF distally. ${ }^{14}$ The Trk receptor traveled in a signaling endosome to the nucleus where it activated various signal cascades, including MAP kinases, ERK5, and PI3 kinase, to influence gene activation and protein expression and thereby promote neuronal survival. Retrograde transport of trophic factors is important in developing proper connections during normal development and maturation of the nervous system.

There is also anterograde signaling, documented for BDNF. This may be more important in the nervous system response to stressors after maturation, such as neurotoxins or degenerative disorders. As demonstrated with fluorescently tagged BDNF, the trophic factor traveled in both an anterograde and retrograde fashions. ${ }^{15}$ The distribution of BDNF and its mRNA in the CNS likewise support anterograde transport. ${ }^{16} \mathrm{BDNF}$ is present in many regions that lack BDNF mRNA, indicating that BDNF is synthesized elsewhere. Furthermore, BDNF concentrations were reduced by blocking selective afferents to the target tissue, which contains BDNF but no BDNF mRNA. It is likely that some activation with anterograde mechanisms is through the traditional Trk receptor for BDNF, but other mechanisms not yet well elucidated may also play a role. ${ }^{14}$ Anterograde signaling is likely to be more important in response to cell damage or other situations that result in a change in physiological demand.

In addition to neuron-neuron trophic factor exchange, glia are also a source of neurotrophic factors for neurons. GDNF and MANF are partially or wholly produced and released by glia., ${ }^{7,9}$

\section{NEUROTROPHIC FACTORS IN PARKINSON'S DISEASE}

\section{Potential mechanisms of therapeutic action}

There are a number of actions by which trophic factors could provide important therapeutic effects in PD. The first and most robust effect in the CNS is to promote survival of subpopulations of neurons exposed to toxins and other insults. For PD, neuroprotection is inferred from reduction of dopamine neuron death induced by the relatively specific toxins 1-methyl-4-phenyl-1,2,3,6-tetrahydropyridine (MPTP) and 6-hydroxydopamine (6OHDA), both in vitro and in vivo. If toxin-induced DA neuron death shares any mechanisms with the pathogenesis of PD, this action of trophic factors could slow or stop neurodegeneration of the dopaminergic system and functional decline. Neuroprotective effects could be specific for the dopamine neurons or could be a less specific effect mediated by dampening the inflammatory response. ${ }^{17}$
A second mechanism resulting in therapeutic benefit with trophic agents is the restoration of function of neurons that are losing their dopaminergic phenotype (i.e., the capacity to synthesize and release dopamine). The fact that substantia nigra dopamine neurons are better preserved than is dopamine concentration in the striatum is evidence that dysfunctional neurons are present in human PD. These restorative effects are likely mediated by changes in gene expression and protein synthesis.

A third mechanism of improvement of function is an immediate stimulatory effect on the dopaminergic system. Acute effects on ion channels causing changes in cell excitability occur with some trophic agents.

Finally, it is possible that loss or disruption of specific trophic factors, their receptors, or their signal cascades cause PD. Replacement of the missing trophic factor or other means of stimulating the transduction pathways would be specific therapy for PD. The following sections address the three most studied trophic factors in animal models of PD: BDNF, GDNF, and neurturin.

\section{BDNF}

BDNF is required for the proper number of dopaminergic neurons to develop in the substantia nigra. ${ }^{18}$ It is expressed by dopamine neurons in both the substantia nigra and the ventral tegmental area ${ }^{19,20}$ which suggests that BDNF may function as an autocrine or paracrine factor. It is seen in lesser concentrations in the striatum, ${ }^{20}$ where its actions could be mediated by retrograde or anterograde transport. In postmortem samples, BDNF and BDNF mRNA were lower in the substantia nigra of PD patients than in controls. ${ }^{21,22}$ This reduction may represent loss of dopaminergic neurons that contain the trophic factor.

BDNF protected dopamine neurons in vitro from the neurotoxic effects of 1-methyl-4-phenylpyridinium ion (MPP+) and 6-OHDA. ${ }^{23,24}$ Fibroblasts capable of secreting transgenic human BDNF that were implanted near the substantia nigra of rats prior to striatal MPP+ infusions decreased destruction of dopamine neurons by $86 \%{ }^{25}$ Intrastriatal injection of BDNF in a rat model prior to unilateral 6-OHDA lesioning reduced destruction of dopamine neurons in the substantia nigra and decreased the apomorphine-induced rotation (a measure of asymmetrical dopaminergic function). ${ }^{26}$ Conversely, a knock down of the BDNF receptor, trkB, and the related NT-3 receptor, trkC, result in a reduced number of dopaminergic neurons in the substantia nigra, induced accumulation of $\alpha$-synuclein in remaining dopamine neurons, and reduced tyrosine hydroxylase immunoreactivity in the striatum. ${ }^{27}$ Furthermore, BDNF genetic variants have been reported to influence the age of onset of $\mathrm{PD}$ in familial PD. ${ }^{28}$ Despite the evidence that BDNF is 
neuroprotective in animal models of PD, there are no studies suggesting that it has a restorative action on the dopaminergic system in experimental animals.

\section{GDNF}

GDNF supports the development of embryonic dopamine neurons relatively specifically ${ }^{7}$ and is particularly important for postnatal survival of mesencephalic dopamine neurons. ${ }^{29}$ It is present in the striatum and despite, being named glial-derived growth factor, may reside largely in the striatal medium spiny neurons that receive dopaminergic input from the substantia nigra. ${ }^{30}$ GDNF levels in various parts of the brain are reported to be no different in parkinsonian than in control patient brains. ${ }^{31}$ GDNF mRNA expression was increased in the putamen of PD patients, however, compared with controls, ${ }^{32}$ and so there is no evidence that loss of GDNF is responsible for development of PD.

A variety of experiments in rodent models have shown that GDNF directly injected into the substantia nigra or striatum protects dopaminergic neurons from neurotoxins. ${ }^{33-36}$ Elevating GDNF in the striatum by gene therapy is also protective. ${ }^{37-39}$ Unlike the case with BDNF, however, there is also evidence for restoration of function of injured neurons by GDNF after toxic insults ${ }^{33,36,40}$ although restorative actions are generally not as dramatic as the neuroprotective actions. ${ }^{33} \mathrm{~A}$ series of influential studies from Gash, Gerhardt, and coworkers ${ }^{41-43}$ have demonstrated GDNF-induced improvement in bradykinesia, rigidity, and postural instability in monkeys with stable MPTP-induced hemiparkinsonism. GDNF was effective when given by bolus or by constant infusion, and through three routes of administration: intranigral, intrastriatal, and intracerebroventricular (ICV). These studies, showing clear improvement in monkeys with established hemiparkinsonism, stimulated the clinical trials that followed.

In addition to neuroprotective and neurorestorative actions, GDNF also has direct effects on dopamine neurons, modulating excitability via changes in A-type potassium channels. ${ }^{44}$ This may be a mechanism by which GDNF acutely increases dopamine release. ${ }^{45}$

\section{Neurturin}

Neurturin (NRTN; also known as NTN) is a naturally occurring structural and functional analog of GDNF that binds to the GFR $\alpha 1$ and GFR $\alpha 2$ receptors coupled to RET. ${ }^{46}$ Neurturin has been shown to enhance survival of dopaminergic neurons both in vitro, and in rodent and monkey models of PD. ${ }^{47-53}$ Evidence for restoration has also been found in rodents treated with 6-OHDA ${ }^{52}$ and in aged monkeys, in which there is an age-related loss of dopaminergic phenotype ${ }^{54}$ In the later studies, an adenoassociated type 2 viral vector that encoded for human NRTN was injected unilaterally into the striatum of the aged rhesus monkeys. $\left[{ }^{18} \mathrm{~F}\right]$ Fluorodopa uptake was increased in the NRTN vector-treated striatum, compared with the uninjected side, at 4 and 8 months. Postmortem examination also revealed an increase in tyrosine hydroxylase immunoreactivity in the injected striatum, relative to the uninjected side. ${ }^{54}$

A number of other trophic factors have a protective effect on dopamine neurons in vitro and in vivo. These other factors are generally less well characterized, but potentially have clinical implications (Table 2). It is important to keep in mind in reviewing all these studies that they all focus on effects on dopamine neurons. Although dopamine loss is a key factor in PD, the pathology extends beyond the dopamine neuron and motor function, ${ }^{55}$ which opens the field to other trophic factors with no effect on the dopaminergic system.

TABLE 2. Other Trophic Factors with Effects on Dopaminergic Neurons

\begin{tabular}{|c|c|c|c|c|}
\hline Factor & Symbol & $\begin{array}{l}\text { Protective } \\
\text { Actions } \\
\text { (Model) }\end{array}$ & $\begin{array}{l}\text { Restorative } \\
\text { Actions } \\
\text { (Model) }\end{array}$ & Reference \\
\hline $\begin{array}{l}\text { Conserved dopamine } \\
\text { neurotrophic factor }\end{array}$ & $\mathrm{CDNF}$ & 6-OHDA rats & 6-OHDA rats & Lindholm et al. ${ }^{10}$ (2007) \\
\hline Erythropoietin & EPO & 6-OHDA rats & MPTP mice & $\begin{array}{l}\text { Puskovic et al al.99 (2006); } \\
\quad \text { Xue et al. }{ }^{100}(2007)\end{array}$ \\
\hline $\begin{array}{l}\text { Pituitary adenylate cyclase } \\
\text { activating polypeptide }\end{array}$ & PACAP & 6-OHDA rats & Not studied & Reglodi et al. ${ }^{101}(2004)$ \\
\hline Persephin & PSPN & 6-OHDA mice & Not studied & Akerud et al. ${ }^{102}$ (2002) \\
\hline $\begin{array}{l}\text { Vasoactive intestinal } \\
\text { peptide }\end{array}$ & VIP & MPTP mice & Not studied & Delgado et al. ${ }^{17}$ (2003) \\
\hline $\begin{array}{l}\text { Insulin-like growth factor } \\
\text { type } 1\end{array}$ & IGF1 & 6-OHDA rats & 6-OHDA rats & $\begin{array}{l}\text { Krishnamurthi et al. }{ }^{103} \\
(2004)\end{array}$ \\
\hline Fibroblast growth factor & FGF* & 6-OHDA rats & MPTP monkey & $\begin{array}{l}\text { Shults et al. }{ }^{104}(2000) ; \\
\text { Fontan et al. }^{12}(2002)\end{array}$ \\
\hline
\end{tabular}

MPTP = 1-methyl-4-phenyl-1,2,3,6-tetrahydropyridine; 6-OHDA = 6-hydroxydopamine.

*bFGF for MPTP monkey; FGF2 for 6-OHDA rats. 


\section{MANIPULATING TROPHIC FACTORS FOR THERAPEUTIC BENEFIT}

Major barriers to translating neurotrophic factor research from the bench to the bedside involve the challenges in delivery to the appropriate cells in the CNS, generally dopaminergic nerve terminals and cell bodies. The most important among these barriers, and pervasive in the treatment of CNS disorders, is penetration of the blood-brain barrier (BBB). The large size of the trophic factor proteins and their chemical structure makes entry into the CNS after peripheral delivery unlikely. Thus, an emphasis in the field of neurotherapeutics of trophic factors has been methods of delivery of potential therapeutic agents to the brain or spinal cord. When that problem is resolved, a second concern likely to arise is the consequence of trophic factor delivery to unintended CNS structures.

The most obvious means of bypassing the BBB is via injection into the lumbar or ventricular CSF. The lumbar CSF has been used to administer trophic agents that potentially could affect motor neurons in amyotrophic lateral sclerosis, ${ }^{56}$ and the ventricular CSF has been used for diseases affecting the brain stem and hemispheres, such as Alzheimer's disease and PD. ${ }^{42,57}$ Intracerebroventricular injection of GDNF in the monkeys with MPTP-induced parkinsonism increased the number and size of dopaminergic neurons in the midbrain, as well as increasing dopamine levels, in both parkinsonian and normal monkeys. ${ }^{41,58}$ This method of delivery of GDNF was not, however, successful in humans. It is extremely likely that in humans a protein trophic factor would not diffuse from ventricular ependyma to the putamen, which in the much larger human brain lies more than 1 $\mathrm{cm}$ away from the ventricles.

Direct infusion of trophic factors or viral vectors into the parenchyma is another method of delivery to the intended target. The problem with this technique is that there is limited movement of proteins through the brain parenchyma by diffusion. Direct injection of GDNF into the brain appeared to be effective in a monkeys with MPTP-induced parkinsonism. ${ }^{59,60}$

Diffusion is based on a concentration gradient of the infused agent around the tip of the intraparenchymal catheter. An alternative method of intraparenchymal infusion is to use hydrostatic pressure to create a pressure gradient around the catheter tip. The infused agent then moves by bulk flow. ${ }^{61}$ This infusion into interstitial space with pressure, referred to as convection-enhanced delivery, produces a more widespread delivery of the agent than does diffusion. Convection-enhanced delivery has been used with GDNF in monkeys and in humans. ${ }^{60,62}$ It has also been used to deliver viral vectors. ${ }^{63}$ Convection-enhanced delivery raises the question of possible delivery of proteins or viral vectors to unintended
CNS targets, because agents delivered in this manner often do not respect the anatomical boundaries of the nuclei into which they are injected.

Temporarily disrupting the BBB to allow molecules normally excluded from the CNS to cross is a theoretical option for delivery of viral vectors with trophic factor genes. Infusion of a hyperosmotic agent (e.g., mannitol) will temporarily disrupt the $\mathrm{BBB}^{64}$ and permit delivery of viral vectors. ${ }^{65}$ With this technique, targeting is restricted to the vascular distribution of the vessel through which the hyperosmotic agent is administered. This may limit targeting of the vector to specific structures.

Another invasive strategy to raise the concentration of therapeutic trophic factors in a target tissue is implantation of cells programmed to make and secrete the trophic factor of interest. A promising approach is to use human neural progenitor cells isolated from postmortem fetal brain. These cells have the unique feature of migrating after intracerebral transplantation, unlike other cells that have been transplanted into brain. Human neural progenitor cells engineered to secrete GDNF and implanted into the striatum of rats migrated so that they were distributed throughout most of the of the striatum and increased dopamine neuron survival and fiber proliferation. ${ }^{66}$

Although trophic factors generally do not readily penetrate the BBB, there are clever means to link them to an endogenous peptide or peptidomimetic monoclonal antibody that undergoes receptor mediated transcytosis carried into brain..$^{67} \mathrm{BDNF}$ linked to a monoclonal antibody transported by the transferrin receptor entered the brain of rats and protected the CA1 hippocampal neurons from an ischemic insult. ${ }^{68}$ Another Trojan-horse strategy uses nanotechnology, whereby the chemical properties of the trophic factor can be disguised in nanoparticles. These submicroscopic nanoparticles generally consist of synthetic or natural polymer aggregates that form spheres in which the drug is encapsulated, attached, dissolved, or entrapped. By hiding the trophic factor within the nanoparticle, the chemical properties are masked and the trophic factor can cross the BBB along with its nanoparticle carrier. $^{69}$

Even if a trophic factor cannot as such cross the BBB, fragments of it may cross. A large portion of the trophic factor may not be imperative for initiating the desired signaling cascade. Smaller, bioactive fragments may be better able to cross the BBB. One example of this potential approach is glycine-proline-glutamate (GPE), which is naturally cleaved from insulin-like growth 1 (IGF-1). Intraperitoneally administered GPE reduced apomorphine rotations in rats unilaterally lesioned with 6-OHDA, compared with controls. ${ }^{70}$ Along this line, small peptides have been created that directly activate the Trk receptor for neurotrophins and initiate neurotrophin signaling. ${ }^{71}$

Small molecules that cross the BBB and directly stim- 
ulate receptors or transduction mechanisms of trophic factors suggest an alluring strategy to generate trophic actions in the CNS. ${ }^{8}$ For example, a small, nonpeptide quinol can activate the GDNF receptor-RET complex. ${ }^{72}$ High-throughput screening techniques could be used to search for candidate drugs that act by this mechanism. A related but invasive method to bypass the trophic factor or its receptor is to use viral vectors that carry genes for the signaling pathways for trophic factors. Insertion of the gene for the oncoprotein $\mathrm{Akt} / \mathrm{PKB}$, which is activated by GDNF and other trophic factors, into the striatum of mice not only protected the mice from 6-OHDA but also promoted regeneration after 6-OHDA. ${ }^{73}$

Increasing brain levels of neurotrophic factors may also be feasible by indirect means. Smaller molecules may upregulate trophic factor expression or release. Ibogaine, an alkaloid extracted from the root of the African shrub Tabernanthe iboga, and used to treat alcohol addiction, increases the expression of GDNF in the midbrain. ${ }^{74}$ Likewise, antidepressants increase the expression of BDNF in the rat hippocampus. ${ }^{75}$

Finally, completely nondrug methods may be used to increase trophic factor concentrations in certain areas of the brain. Voluntary exercise increases the concentrations of BDNF in the hippocampus of rats. ${ }^{76}$ Similarly, forced use of the forelimb contralateral to a 6-OHDA lesion (produced by casting the ipsilateral forelimb) reduced vulnerability of dopamine neurons in rats. ${ }^{77,78}$ This protective action of forced use of the limb was attributed to raised concentrations of GDNF in the lesioned striatum 1 and 3 days after casting the ipsilateral forelimb.

\section{CLINICAL STUDIES WITH GDNF AND NEURTURIN}

\section{Intracerebroventricular administration of GDNF}

Preclinical investigations demonstrated the effectiveness of monthly ICV injections of GDNF in monkeys with MPTP-induced hemiparkinsonism. ${ }^{41,42}$ These studies suggested that ICV administration, an acceptable route for administering other drugs in monkeys, could be a method to administer GDNF in patients. On the basis of the evidence that GDNF was neuroprotective and neurorestorative in rodents and the efficacy in monkeys via the ICV route, Amgen (Newbury Park, CA) sponsored a phase I-II multicenter, randomized, double-blind, placebocontrolled, dose-escalation trial with human recombinant methionyl GDNF in subjects with advanced PD. The human recombinant GDNF made with Escherichia coli was biologically active, but differed from endogenous GDNF in that it was not glycosylated. This was the same formulation of GDNF used in the monkey studies. The sequential cohort study design examined the effects of placebo, $25,75,150,300$, and 500 to $4000 \mu \mathrm{g}$ of GDNF administered monthly for up to 28 months through an implanted subcutaneous port attached to an intraventricular cannula.

GDNF was biologically active by this route at even the lowest dose, $25 \mu \mathrm{g} .{ }^{79}$ A common acute effect of ICV injection of GDNF was anorexia and nausea, which came on an hour to a day later and could last for days. Weight loss was common, even without accompanying anorexia. At the end of the study, however, subjects regained weight, which seemed to correlate with an increase in appetite. Hyponatremia, generally asymptomatic, occurred in half the subjects. Sensory symptoms, frequently described as electric shocks (Lhermitte sign) were common. There was no improvement of any aspect of the parkinsonism. Autopsy of the brain in a subject who died from unrelated causes during the trial showed minimal penetration of GDNF into the brain parenchyma and no evidence of enhancement of tyrosine hydroxylase activity in the putamen. ${ }^{80}$ This suggests that one explanation for the lack of improvement in parkinsonism in the trial was that ICV-administered GDNF did not reach its intended target.

\section{Intraputaminal administration of GDNF}

Gill et al. ${ }^{81}$ took the next step in the effort to deliver GDNF to the desired target: direct infusion. GDNF was infused directly into the posterior putamen via implanted catheters and SynchroMed pumps (Medtronic, Minneapolis, MN) in five PD subjects in an open trial in Bristol, United Kingdom. The infusions were unilateral in one markedly asymmetrical subject and bilateral in the other four subjects. A rapid and marked improvement over the first 3 months was sustained, leading to a $39 \%$ improvement in "off" score on the motor portion of the Unified Parkinson's Disease Rating Scale (UPDRS) score and a $61 \%$ improvement in the activities of daily living (ADL) portion at 1 year. The improvement was associated with a minimal increase in levodopa equivalents in three subjects and a substantial decrease in two subjects. ${ }^{82}$ However, two of the changes in medications (the addition of cabergoline in one subject and a switch from entacapone to tolcapone in another subject) may have had a larger clinical effect than was captured by levodopa equivalents. ${ }^{82}$ The improvement in UPDRS motor and ADL subscores persisted for 2 years. ${ }^{83}$ Adverse effects of intraputaminal infusion were much less than those seen with intraventricular administration. The anorexia and nausea were absent, as was the hyponatremia; however, some subjects experienced the tingling sensations characterized as Lhermitte's sign. $\left[{ }^{18}\right.$ F]Fluorodopa PET scans after 18 months of GDNF putaminal infusion showed very restricted increase of fluorodopa retention about the tip of the catheter. ${ }^{81}$

The observations of Gill et al. ${ }^{81}$ were the impetus for a randomized, double-blind, placebo-controlled trial of 
bilateral GDNF infusion in 34 subjects with moderately advanced PD, sponsored by Amgen Inc. The trial was designed to replicate the open experience of Gill et al., but the randomized trial differed in that the intraputaminal catheter had a slightly larger outside diameter. The infusion rate was $15 \mu \mathrm{g}$ of GDNF per putamen per day. Gill et al. used $14 \mu \mathrm{g}$ per putamen per day for the majority of the time in their open trial; although the subjects were exposed to $43 \mu \mathrm{g}$ per day for 1 to 3 months during the study before returning to $14 \mu \mathrm{g}$ per day, because of a signal in MRI that developed about the catheter tip with higher concentrations of GDNF. ${ }^{81}$

The randomized trial did not find a significant clinical effect of GDNF; there was a $10 \%$ decrease in the off motor UPDRS scores (a decrease represents improvement) in the treatment group and 5\% decrease in the placebo group. ${ }^{84}$ The results of the $\left[{ }^{18} \mathrm{~F}\right]$ fluorodopa PET scans were similar to those of Gill et al.: a $23 \%$ increase in $\left[{ }^{18} \mathrm{~F}\right]$ fluorodopa uptake restricted to the immediate vicinity of the catheter tip in the subjects receiving GDNF and a 9\% decrease in the subjects receiving placebo infusions. GDNF-binding antibodies appeared in the serum of approximately half the subjects, and GDNFneutralizing antibodies developed in a small subset of these same subjects. ${ }^{85}$ Finally, the concurrent 6-month toxicity studies found a patchy loss of Purkinje cells in some monkeys on high-dose GDNF (100 $\mu \mathrm{g} /$ day $)$. Although there was no toxicity attributable to GDNF in the clinical trials, these findings, added to the lack of efficacy in the randomized clinical trial, led Amgen to discontinue the clinical studies.

A second open trial, published about the same time as the double-blind trial, described unilateral, convectionenhanced delivery of GDNF into the midputamen by a multiport cannula in 10 PD subjects. ${ }^{86,87}$ The convection-enhanced delivery of GDNF in brief pulses was intended to increase bulk flow of the GDNF in the brain. In addition, the GDNF dose was higher than in the other clinical trials, up to $30 \mu \mathrm{g}$ per day. At the end of 1 year, the "off" motor UPDRS improved 45\% and the total UPDRS improved to a similar extent. Somewhat surprisingly, the unilaterally administered GDNF produced a relatively symmetrical bilateral improvement in parkinsonism.

The differences in the results of these three trials have led to much controversy, which continues to the present. A major question relates to the distribution of GDNF in the putamen by the different infusion techniques. A computational evaluation of the distribution of GDNF by the catheters used by Gill et al. and in the Amgen trial found little difference in the estimated distribution of GDNF by the two catheters. ${ }^{88}$ The multiport catheter and the use of convection-enhanced delivery led to a larger volume of distribution, but it was still "comparable to those attained in the other two trials." ${ }^{88}$ An examination of the distri- bution of GDNF in monkeys, using a catheter and infusion protocol as in the randomized clinical trial, indicated that the GDNF concentrations dropped exponentially with increasing distance from the catheter tip and volumes of distribution were variable, ranging from 90 to 370 cubic $\mathrm{mm} .{ }^{89}$ On the other hand, convection-enhanced delivery of GDNF into the putamen of monkeys led to GDNF as far as $11 \mathrm{~mm}$ from the catheter but with backflow into the cortex, spread along white matter tracks, and retrograde and anterograde distribution of GDNF into globus pallidum, caudate, and thalamus. ${ }^{60}$ One subject in the Bristol trial died from a myocardial infarct 3 months after stopping intraputaminal GDNF infusion, which he had received for 43 months. Immunolabeling indicated a marked increase in tyrosine hydroxylase about the catheter tip in the putamen, consistent with the PET findings of a focal increase in $\left[{ }^{18} \mathrm{~F}\right]$ fluorodopa uptake at the catheter tip. In addition, there was a slight increase in lymphocytes, macrophages, and class II antigen-positive microglia as well as glial fibrillary acidic protein within a couple $\mathrm{mm}$ of the catheter tip. In sum, these observations suggest that infusion of GDNF into the putamen of PD subjects may restore dopaminergic function around the tip of the catheter; however, it also suggests that one potential reason for the failure of the randomized clinical trial was the restricted distribution of GDNF in the putamen.

No toxicity from GDNF infusions has emerged in the 2 years of follow-up of the subjects with and without neutralizing antibodies in the randomized clinical trial and the two open trials (a total of 49 subjects). The multifocal cerebellar Purkinje cell loss reported in four monkeys receiving GDNF $100 \mu \mathrm{g} / \mathrm{day}$ remains unexplained, despite extensive investigation of the postmortem tissues. ${ }^{90}$ No cerebellar toxicity has been clinically recognized, and there have been no abnormalities detected in a careful analysis of MRI images of cerebellum before and after GDNF treatment in patients ${ }^{91}$ (in the monkeys, any cerebellar lesions would not have been evident with MRI). The one subject from the Bristol trial who came to autopsy had "old, probably ischemic, scarring in the watershed region of the cerebellum and small neuronal heterotopias in the cerebellar white matter"92 which, superficially at least, sounds as though the cerebellar pathology was different from that seen in the highdose GDNF monkeys.

The Amgen trial design and the analysis of the results has been debated in the literature..$^{93,94}$ A persistent placebo effect over several years has been deemed unlikely by some critics, but there was evidence for a prolonged placebo response in a double-blind trial of embryonic dopaminergic grafting. ${ }^{95}$ The Michael J. Fox Foundation for Parkinson's Research and the Kinetics Foundation held a meeting of researchers with expertise in relevant fields to discuss the issues and uncertainties raised by 
these trials; this discussion, in turn, led to a thoughtful comparison of the studies and suggestions of how to move forward the study of trophic factors in PD. ${ }^{96}$ These three clinical proof-of-principle studies have raised a number of questions that require further investigation. The uncertainties surrounding the trials of intraputaminal infusion of GDNF should not end the search for therapeutic benefit from neurotrophic factors.

\section{Gene therapy with neurturin}

The next and ongoing step in bringing trophic factors into therapy for PD was to use gene therapy to deliver the neurotrophic factor. Because Amgen held the patent on GDNF, Ceregene (San Diego, CA) has used NRTN (neurturin), another member of the GDNF-like family of trophic factor signaling through the same receptor family and RET activation. ${ }^{8}$ Neurturin has been demonstrated to be neuroprotective in a number of animal models of parkinsonism. The evidence that it is neurorestorative is more limited. ${ }^{52,54}$ The NRTN gene (alias NTN) is delivered in serotype 2 adeno-associated virus that specifically targets neurons. The vector is delivered by four stereotaxic injections into each putamen, with two infusions of vector at the inferior and superior part of the putamen. This adds up to eight injections per putamen and a total of 16 infusion sites per subject. A phase I trial on safety and tolerability of NRTN delivered at two doses in 12 PD subjects reported good tolerability and no toxicity. The UPDRS in the practical "off" state was reported to improve $30-40 \%$, with a few exceptions. It must be recalled that this is an open and uncontrolled study, and there are large numbers of placebo responses in surgical trials. ${ }^{95}$ Nonetheless, based on these encouraging results and good safety and tolerability, a phase II, randomized, double-blinded, sham-controlled, clinical trial had, as of writing, just completed enrollment, with results being expected in a little more than 1 year.

\section{CONCLUSION}

Multiple studies in vitro and in animal models of PD indicate that a number of trophic factors have the potential to be powerful therapeutic agents to halt or restore function in the dopaminergic system. This promise for the dopaminergic system is also a limitation, however. It is increasingly recognized that much more than just the dopaminergic system is affected in PD, and that even restoration of the dopaminergic system is unlikely to reverse all the motor symptoms, much less the cognitive, emotional, sleep, and autonomic problems that are part of the disease. ${ }^{55}$ The neurotrophic factors that are considered for use in humans are selected by their effects on dopamine neurons in in vitro and in vivo laboratory models. Other trophic factors that do not have a promi- nent effect on the dopaminergic system may still have therapeutic potential for PD.

Nevertheless, knowing that the dopaminergic system is important for motor function, and having trophic factors that were selected for their action on the dopaminergic system narrows down the nuclei that are targets for delivery of these agents. At present, the major issue is delivery of trophic factors to appropriate CNS targets, generally regarded to be the striatum for PD. ${ }^{36}$ Delivery has two components: getting the agent to the appropriate tissue, a probable reason for failure of ICV administration of GDNF, and distribution within the target tissue, a possible reason for failure of the randomized clinical trial with GDNF.

The intraputaminal administration of adeno-associated viral vectors with the neurturin gene into eight sites of each putamen is an attempt to solve both of these problems. All three methods of trophic factor delivery tried to date are invasive, although associated with little serious morbidity and no mortality. What the field needs, however, is proof of principle, and these studies were planned with this in mind. Proof of principle for neurotrophic factors would stimulate research into better methods of delivery, and there are many possibilities.

Two other issues related to delivery have received less attention: dose and spread of trophic factor to other areas of the CNS. The ICV administration of GDNF to primates with intracarotid MPTP-induced hemiparkinsonism produced a dose-responsive antiparkinsonian effect. ${ }^{42}$ However, delivery of GDNF gene by lentivirus to rats resulted in higher levels of expression of GDNF in striatum than with other vectors for gene delivery. ${ }^{38}$ This high level of GDNF expression protected dopaminergic neurons, but produced no functional recovery as measured by spontaneous motor behavior. The lack of functional recovery was attributed to downregulation of tyrosine hydroxylase and to aberrant sprouting in the globus pallidus and the substantia nigra. In turn, the aberrant sprouting was attributed to anterograde transport of GDNF from the striatum to these nuclei. ${ }^{38}$ The dose of trophic factor may be one variable influencing the response.

Convection-enhanced delivery of GDNF to the monkey putamen resulted in GDNF diffusing to the putamen, caudate, globus pallidus, and internal and external capsule. ${ }^{60}$ GDNF also spread by the external capsule to the amygdala, by backflow along the catheter track to the cortex, by the internal capsule and the corticospinal tract to the spinal cord, and by retrograde transport to the thalamus. Likewise, convection-enhanced delivery of adeno-associated virus type 2 with the genes for aromatic amino acid decarboxylase and for thymidine kinase to the putamen of primates showed expression for the genes in approximately $75 \%$ of the putamen. However, there was also spread of the vector and enzyme expression in 
the globus pallidus, subthalamic nucleus, thalamus, and the substantia nigra. The clinical importance of spread of trophic factor itself or its gene beyond the striatum is unknown.

Immunological responses to the trophic factor or to viral vectors is another area in which we lack information. Administering antibodies against another endogenous trophic factor, erythropoietin, produces a severe anemia. ${ }^{1}$ To date, the antibodies (and, specifically, neutralizing antibodies) seen in a few subjects in the intraputaminal GDNF infusion studies have not had any recognized medical consequences. Adeno-associated viruses have low immunogenicity and toxicity, but are not completely devoid of such effects. ${ }^{97}$ The immunogenicity of adeno-associated viruses may be amenable to molecular engineering. ${ }^{98}$

One other point about the design of the clinical trials with trophic factors should be noted. Trophic factors in the CNS have been defined as peptides that both protect and (sometimes) restore function in specific subpopulations of neurons. The studies so far conducted have, by necessity, focused on restoration of motor function. These trials have been small, short, and expensive. However, clinical trials designed for restorative effects may miss the robust protective actions of trophic factors seen in animal models of PD. The consequence is that we may not detect an important effect of trophic factors: slowing the progression of the disease process and preservation of motor function. Trials with neuroprotection or delayed motor deterioration as endpoints will likely require larger numbers of subjects, longer trials, and probably an earlier stage of PD than have characterized the trials to date. However, the possibility that the disease process is slowed in subjects treated with trophic factors should be considered even in these early clinical trials seeking restorative actions.

Despite the intricacies of translating the laboratory findings with trophic agents into clinical treatments, the efficacy of trophic factors as neuroprotective and neurorestorative therapies in animal models of PD will ensure continued efforts to bring these agents into therapeutic trials and eventually clinical practice.

Acknowledgments: This work was supported in part by the Northwest Parkinson's Disease Research, Education and Clinical Center (PADRECC) of the U.S. Department of Veterans Affairs and by the National Institutes of Health (grant R01-NS21062).

\section{REFERENCES}

1. Bennett CL, Luminari S, Nissenson AR, et al. Pure red-cell aplasia and epoetin therapy. N Engl J Med 2004;351:1403-1408.

2. Cohen S, Levi-Montalcini R, Hamburger V. A nerve growthstimulating factor isolated from sarcomas 37 and 180. Proc Natl Acad Sci U S A 1954;40:1014-1018.

3. Marti HH, Wenger RH, Rivas LA, et al. Erythropoietin gene expression in human, monkey and murine brain. Eur J Neurosci 1996;8:666-676.
4. Butte MJ. Neurotrophic factor structures reveal clues to evolution, binding, specificity, and receptor activation. Cell Mol Life Sci 2001;58:1003-1013.

5. Maisonpierre PC, Belluscio L, Friedman B, et al. NT-3, BDNF, and NGF in the developing rat nervous system: parallel as well as reciprocal patterns of expression. Neuron 1990;5:501-509.

6. Maisonpierre PC, Le Beau MM, Espinosa R III, et al. Human and rat brain-derived neurotrophic factor and neurotrophin-3: gene structures, distributions, and chromosomal localizations. Genomics 1991;10:558-568.

7. Lin LF, Doherty DH, Lile JD, Bektesh S, Collins F. GDNF: A glial cell line-derived neurotrophic factor for midbrain dopaminergic neurons. Science 1993;260:1130-1132.

8. Bespalov MM, Saarma M. GDNF family receptor complexes are emerging drug targets. Trends Pharmacol Sci 2007;28:68-74.

9. Petrova P, Raibekas A, Pevsner J, et al. MANF: a new mesencephalic, astrocyte-derived neurotrophic factor with selectivity for dopaminergic neurons. J Mol Neurosci 2003;20:173-188.

10. Lindholm P, Voutilainen MH, Lauren J, et al. Novel neurotrophic factor CDNF protects and rescues midbrain dopamine neurons in vivo. Nature 2007;448:73-77.

11. Shults CW. Neurotrophic factors. In: Watts RL, Koller WC, editors. Movement disorders: neurologic principles and practice. 2nd ed. New York: McGraw-Hill, 2004;131-142.

12. Fontan A, Rojo A, Sanchez-Pernaute R, et al. Effects of fibroblast growth factor and glial-derived neurotrophic factor on akinesia, F-DOPA uptake and dopamine cells in parkinsonian primates. Parkinsonism Relat Disord 2002;8:311-323.

13. Levi-Montalcini R. The nerve growth factor 35 years later. Science 1987;237:1154-1162.

14. Heerssen HM, Segal RA. Location, location, location: a spatial view of neurotrophin signal transduction. Trends Neurosci 2002; 25:160-165.

15. Kohara K, Kitamura A, Morishima M, Tsumoto T. Activitydependent transfer of brain-derived neurotrophic factor to postsynaptic neurons. Science 2001;291:2419-2423.

16. Conner JM, Lauterborn JC, Yan Q, Gall CM, Varon S. Distribution of brain-derived neurotrophic factor (BDNF) protein and mRNA in the normal adult rat CNS: evidence for anterograde axonal transport. J Neurosci 1997;17:2295-2313.

17. Delgado M, Ganea D. Neuroprotective effect of vasoactive intestinal peptide (VIP) in a mouse model of Parkinson's disease by blocking microglial activation. FASEB J 2003;17:944-946.

18. Baquet ZC, Bickford PC, Jones KR. Brain-derived neurotrophic factor is required for the establishment of the proper number of dopaminergic neurons in the substantia nigra pars compacta. J Neurosci 2005;25:6251-6259.

19. Seroogy KB, Lundgren KH, Tran TM, Guthrie KM, Isackson PJ, Gall CM. Dopaminergic neurons in rat ventral midbrain express brain-derived neurotrophic factor and neurotrophin-3 mRNAs. J Comp Neurol 1994;342:321-334.

20. Zhang HT, Li LY, Zou XL, et al. Immunohistochemical distribution of NGF, BDNF, NT-3, and NT-4 in adult rhesus monkey brains. J Histochem Cytochem 2007;55:1-19.

21. Mogi M, Togari A, Kondo T, et al. Brain-derived growth factor and nerve growth factor concentrations are decreased in the substantia nigra in Parkinson's disease. Neurosci Lett 1999;270: $45-48$.

22. Howells DW, Porritt MJ, Wong JY, et al. Reduced BDNF mRNA expression in the Parkinson's disease substantia nigra. Exp Neurol 2000;166:127-135.

23. Hyman C, Hofer M, Barde YA, et al. BDNF is a neurotrophic factor for dopaminergic neurons of the substantia nigra. Nature 1991;350:230-232.

24. Spina MB, Hyman C, Squinto S, Lindsay RM. Brain-derived neurotrophic factor protects dopaminergic cells from 6-hydroxydopamine toxicity. Ann N Y Acad Sci 1992;648:348-350.

25. Frim DM, Uhler TA, Galpern WR, Beal MF, Breakefield XO, Isacson $\mathrm{O}$. Implanted fibroblasts genetically engineered to produce brain-derived neurotrophic factor prevent 1-methyl-4-phenylpyridinium toxicity to dopaminergic neurons in the rat. Proc Natl Acad Sci U S A 1994;91:5104-5108. 
26. Shults CW, Kimber T, Altar CA. BDNF attenuates the effects of intrastriatal injection of 6-hydroxydopamine. Neuroreport 1995; 6:1109-1112.

27. von Bohlen und Halbach O, Minichiello L, Unsicker K. Haploinsufficiency for trkB and trkC receptors induces cell loss and accumulation of accumulation of $\alpha$-synuclein in the substantia nigra. FASEB J 1919;1740-1742.

28. Karamohamed S, Latourelle JC, Racette BA, et al. BDNF genetic variants are associated with onset age of familial Parkinson disease: GenePD Study. Neurology 2005;65:1823-1825.

29. Granholm AC, Reyland M, Albeck D, et al. Glial cell line-derived neurotrophic factor is essential for postnatal survival of midbrain dopamine neurons. J Neurosci 2000;20:3182-3190.

30. Oo TF, Ries V, Cho J, Kholodilov N, Burke RE. Anatomical basis of glial cell line-derived neurotrophic factor expression in the striatum and related basal ganglia during postnatal development of the rat. J Comp Neurol 2005;484:57-67.

31. Mogi M, Togari A, Kondo T, et al. Glial cell line-derived neurotrophic factor in the substantia nigra from control and parkinsonian brains. Neurosci Lett 2001;300:179-181.

32. Bäckman CM, Shan L, Zhang YJ, et al. Gene expression patterns for GDNF and its receptors in the human putamen affected by Parkinson's disease: a real-time PCR study. Mol Cell Endocrinol 2006;252:160-166.

33. Tomac A, Lindqvist E, Lin LF, et al. Protection and repair of the nigrostriatal dopaminergic system by GDNF in vivo. Nature 1995;373:335-339.

34. Kearns CM, Gash DM. GDNF protects nigral dopamine neurons against 6-hydroxydopamine in vivo. Brain Res 1995;672:104111.

35. Kirik D, Georgievska B, Björklund A. Localized striatal delivery of GDNF as a treatment for Parkinson disease. Nat Neurosci 2004;7:105-110.

36. Kirik D, Rosenblad C, Björklund A. Preservation of a functional nigrostriatal dopamine pathway by GDNF in the intrastriatal 6-OHDA lesion model depends on the site of administration of the trophic factor. Eur J Neurosci 2000;12:3871-3882.

37. Kordower JH, Emborg ME, Bloch J, et al. Neurodegeneration prevented by lentiviral vector delivery of GDNF in primate models of Parkinson's disease. Science 2000;290:767-773.

38. Georgievska B, Kirik D, Björklund A. Aberrant sprouting and downregulation of tyrosine hydroxylase in lesioned nigrostriatal dopamine neurons induced by long-lasting overexpression of glial cell line derived neurotrophic factor in the striatum by lentiviral gene transfer. Exp Neurol 2002;177:461-474.

39. Eslamboli A, Georgievska B, Ridley RM, et al. Continuous lowlevel glial cell line-derived neurotrophic factor delivery using recombinant adeno-associated viral vectors provides neuroprotection and induces behavioral recovery in a primate model of Parkinson's disease. J Neurosci 2005;25:769-777.

40. Kirik D, Georgievska B, Rosenblad C, Björklund A. Delayed infusion of GDNF promotes recovery of motor function in the partial lesion model of Parkinson's disease. Eur J Neurosci 2001; 13:1589-1599.

41. Gash DM, Zhang Z, Ovadia A, et al. Functional recovery in parkinsonian monkeys treated with GDNF. Nature 1996;380: 252-255.

42. Zhang Z, Miyoshi Y, Lapchak PA, et al. Dose response to intraventricular glial cell line-derived neurotrophic factor administration in parkinsonian monkeys. J Pharmacol Exp Ther 1997;282: 1396-1401.

43. Grondin R, Zhang Z, Yi A, et al. Chronic, controlled GDNF infusion promotes structural and functional recovery in advanced parkinsonian monkeys [Comment in: Brain 2002;125:2149-2151]. Brain 2002;125:2191-2201.

44. Yang F, Feng L, Zheng F, et al. GDNF acutely modulates excitability and A-type $\mathrm{K}+$ channels in midbrain dopaminergic neurons. Nat Neurosci 2001;4:1071-1078.

45. Hebert MA, Van Horne CG, Hoffer BJ, Gerhardt GA. Functional effects of GDNF in normal rat striatum: presynaptic studies using in vivo electrochemistry and microdialysis. J Pharmacol Exp Ther 1996;279:1181-1190.

46. Kotzbauer PT, Lampe PA, Heuckeroth RO, et al. Neurturin, a relative of glial-cell-line-derived neurotrophic factor. Nature 1996;384:467-470.

47. Horger BA, Nishimura MC, Armanini MP, et al. Neurturin exerts potent actions on survival and function of midbrain dopaminergic neurons. J Neurosci 1998;18:4929-4937.

48. Hoane MR, Gulwadi AG, Morrison S, Hovanesian G, Lindner $\mathrm{MD}$, Tao W. Differential in vivo effects of neurturin and glial cell-line-derived neurotrophic factor. Exp Neurol 1999;160:235243.

49. Li H, He Z, Su T, et al. Protective action of recombinant neurturin on dopaminergic neurons in substantia nigra in a rhesus monkey model of Parkinson's disease. Neurol Res 2003;25:263-267.

50. Kordower JH, Herzog CD, Dass B, et al. Delivery of neurturin by AAV2 (CERE-120)-mediated gene transfer provides structural and functional neuroprotection and neurorestoration in MPTPtreated monkeys. Ann Neurol 2006;60:706-715.

51. Rosenblad C, Kirik D, Devaux B, Moffat B, Phillips HS, Björklund A. Protection and regeneration of nigral dopaminergic neurons by neurturin or GDNF in a partial lesion model of Parkinson's disease after administration into the striatum or the lateral ventricle. Eur J Neurosci 1999;11:1554-1566.

52. Oiwa Y, Yoshimura R, Nakai K, Itakura T. Dopaminergic neuroprotection and regeneration by neurturin assessed by using behavioral, biochemical and histochemical measurements in a model of progressive Parkinson's disease. Brain Res 2002;947: 271-283.

53. Tseng JL, Bruhn SL, Zurn AD, Aebischer P. Neurturin protects dopaminergic neurons following medial forebrain bundle axotomy. Neuroreport 1998;9:1817-1822.

54. Herzog CD, Dass B, Holden JE, et al. Striatal delivery of CERE120 , an AAV2 vector encoding human neurturin, enhances activity of the dopaminergic nigrostriatal system in aged monkeys. Mov Disord 2007;22:1124-1132.

55. Langston JW. The Parkinson's complex: parkinsonism is just the tip of the iceberg. Ann Neurol 2006;59:591-596.

56. Beck M, Flachenecker P, Magnus T, et al. Autonomic dysfunction in ALS: a preliminary study on the effects of intrathecal BDNF. Amyotroph Lateral Scler Other Motor Neuron Disord 2005;6:100-103.

57. Fischer W, Wictorin K, Björklund A, Williams LR, Varon S, Gage FH. Amelioration of cholinergic neuron atrophy and spatial memory impairment in aged rats by nerve growth factor. Nature 1987;329:65-68.

58. Gash DM, Zhang Z, Cass WA, et al. Morphological and functional effects of intranigrally administered GDNF in normal rhesus monkeys. J Comp Neurol 1995;363:345-358.

59. Oiwa Y, Nakai K, Itakura T. Histological effects of intraputaminal infusion of glial cell line-derived neurotrophic factor in Parkinson disease model macaque monkeys. Neurol Med Chir (Tokyo) 2006;46:267-275; discussion 275-276.

60. Ai Y, Markesbery W, Zhang Z, et al. Intraputamenal infusion of GDNF in aged rhesus monkeys: distribution and dopaminergic effects. J Comp Neurol 2003;461:250-261.

61. Laske DW, Morrison PF, Lieberman DM, et al. Chronic interstitial infusion of protein to primate brain: determination of drug distribution and clearance with single-photon emission computerized tomography imaging. J Neurosurg 1997;87:586-594.

62. Slevin JT, Gash DM, Smith CD, et al. Unilateral intraputamenal glial cell line-derived neurotrophic factor in patients with Parkinson disease: response to 1 year of treatment and 1 year of withdrawal. J Neurosurg 2007;106:614-620.

63. Hadaczek P, Kohutnicka M, Krauze MT, et al. Convection-enhanced delivery of adeno-associated virus type 2 (AAV2) into the striatum and transport of AAV2 within monkey brain. Hum Gene Ther 2006;17:291-302.

64. Doolittle ND, Miner ME, Hall WA, et al. Safety and efficacy of a multicenter study using intraarterial chemotherapy in conjunction with osmotic opening of the blood-brain barrier for the treatment of patients with malignant brain tumors. Cancer 2000; 88:637-647.

65. Muldoon LL, Nilaver G, Kroll RA, et al. Comparison of intracerebral inoculation and osmotic blood-brain barrier disruption for 
delivery of adenovirus, herpesvirus, and iron oxide particles to normal rat brain. Am J Pathol 1995;147:1840-1851.

66. Behrstock S, Ebert A, McHugh J, et al. Human neural progenitors deliver glial cell line-derived neurotrophic factor to parkinsonian rodents and aged primates. Gene Ther 2006;13:379-388.

67. Pardridge WM. Targeting neurotherapeutic agents through the blood-brain barrier. Arch Neurol 2002;59:35-40.

68. Wu D, Pardridge WM. Neuroprotection with noninvasive neurotrophin delivery to the brain. Proc Natl Acad Sci U S A 1999; 96:254-259.

69. Juillerat-Jeanneret L, Schmitt F. Chemical modification of therapeutic drugs or drug vector systems to achieve targeted therapy: looking for the grail. Med Res Rev 2007;27:574-590.

70. Guan J, Krishnamurthi R, Waldvogel HJ, Faull RL, Clark R, Gluckman P. N-terminal tripeptide of IGF-1 (GPE) prevents the loss of TH positive neurons after 6-OHDA induced nigral lesion in rats. Brain Res 2000;859:286-292.

71. Peleshok J, Saragovi HU. Functional mimetics of neurotrophins and their receptors. Biochem Soc Trans 2006;34:612-617.

72. Tokugawa K, Yamamoto K, Nishiguchi M, et al. XIB4035, a novel nonpeptidyl small molecule agonist for GFR $\alpha$-1. Neurochem Int 2003:42:81-86.

73. Ries V, Henchcliffe C, Kareva T, et al. Oncoprotein Akt/PKB induces trophic effects in murine models of Parkinson's disease. Proc Natl Acad Sci U S A 2006;103:18757-18762.

74. He DY, Ron D. Autoregulation of glial cell line-derived neurotrophic factor expression: implications for the long-lasting actions of the anti-addiction drug, ibogaine. FASEB J 2006;20:24202422.

75. Malberg JE, Blendy JA. Antidepressant action: to the nucleus and beyond. Trends Pharmacol Sci 2005;26:631-638.

76. Adlard PA, Perreau VM, Engesser-Cesar C, Cotman CW. The timecourse of induction of brain-derived neurotrophic factor mRNA and protein in the rat hippocampus following voluntary exercise. Neurosci Lett 2004;363:43-48.

77. Cohen AD, Tillerson JL, Smith AD, Schallert T, Zigmond MJ. Neuroprotective effects of prior limb use in 6-hydroxydopaminetreated rats: possible role of GDNF. J Neurochem 2003;85:299305.

78. Smith AD, Zigmond MJ. Can the brain be protected through exercise? Lessons from an animal model of parkinsonism. Exp Neurol 2003;184:31-39.

79. Nutt JG, Burchiel KJ, Comella CL, et al. Randomized, doubleblind trial of glial cell line-derived neurotrophic factor (GDNF) in PD. Neurology 2003;60:69-73.

80. Kordower JH, Palfi S, Chen E-Y, et al. Clinicopathological findings following intraventricular glial-derived neurotrophic factor treatment in a patient with Parkinson's disease. Ann Neurol 1999; 46:419-424.

81. Gill SS, Patel NK, Hotton GR, et al. Direct brain infusion of glial cell line-derived neurotrophic factor in Parkinson disease. Nat Med 2003;9:589-595.

82. Gill SS, Patel NK, Hotton GR, et al. Addendum: Direct brain infusion of glial cell line-derived neurotrophic factor in Parkinson disease. Nat Med 2006;12:479.

83. Patel NK, Bunnage M, Plaha P, Svendsen CN, Heywood P, Gill SS. Intraputamenal infusion of glial cell line-derived neurotrophic factor in PD: a two-year outcome study. Ann Neurol 2005;57: 298-302.

84. Lang AE, Gill S, Patel NK, et al. Randomized controlled trial of intraputamenal glial cell line-derived neurotrophic factor infusion in Parkinson disease [Erratum in: Ann Neurol 2006;60:747]. Ann Neurol 2006;59:459-466.

85. Tatarewicz SM, Wei X, Gupta S, Masterman D, Swanson SJ, Moxness MS. Development of a maturing T-cell-mediated immune response in patients with idiopathic Parkinson's disease receiving r-metHuGDNF via continuous intraputaminal infusion. J Clin Immunol 2007;27:620-627.
86. Slevin JT, Gerhardt GA, Smith CD, Gash DM, Kryscio R, Young B. Improvement of bilateral motor functions in patients with Parkinson disease through the unilateral intraputaminal infusion of glial cell line-derived neurotrophic factor. J Neurosurg 2005; 102:216-222.

87. Slevin JT, Gash DM, Smith CD, et al. Unilateral intraputamenal glial cell line-derived neurotrophic factor in patients with Parkinson disease: response to 1 year of treatment and 1 year of withdrawal. J Neurosurg 2007;106:614-620.

88. Morrison PF, Lonser RR, Oldfield EH. Convective delivery of glial cell line-derived neurotrophic factor in the human putamen. J Neurosurg 2007;107:74-83.

89. Salvatore MF, Ai Y, Fischer B, et al. Point source concentration of GDNF may explain failure of phase II clinical trial. Exp Neurol 2006;202:497-505.

90. Hovland DN Jr, Boyd RB, Butt MT, et al. Six-month continuous intraputamenal infusion toxicity study of recombinant methionyl human glial cell line-derived neurotrophic factor (r-metHuGDNF) in rhesus monkeys. Toxicol Pathol 2007;35: 1013-1029.

91. Chebrolu H, Slevin JT, Gash DA, et al. MRI volumetric and intensity analysis of the cerebellum in Parkinson's disease patients infused with glial-derived neurotrophic factor (GDNF). Exp Neurol 2006;198:450-456.

92. Love S, Plaha P, Patel NK, Hotton GR, Brooks DJ, Gill SS. Glial cell line-derived neurotrophic factor induces neuronal sprouting in human brain. Nat Med 2005;11:703-704.

93. Hutchinson M, Gurney S, Newson R. GDNF in Parkinson disease: an object lesson in the tyranny of type II. J Neurosci Methods 2007;163:190-192.

94. Matcham J, McDermott MP, Lang AE. GDNF in Parkinson's disease: the perils of post-hoc power. J Neurosci Methods 2007; 163:193-196.

95. McRae C, Cherin E, Yamazaki TG, et al. Effects of perceived treatment on quality of life and medical outcomes in a doubleblind placebo surgery trial [Erratum in: Arch Gen Psychiatry 2004;61:627]. Arch Gen Psychiatry 2004;61:412-420.

96. Sherer TB, Fiske BK, Svendsen CN, Lang AE, Langston JW. Crossroads in GDNF therapy for Parkinson's disease. Mov Disord 2006;21:136-141.

97. Zaiss AK, Muruve DA. Immune responses to adeno-associated virus vectors. Curr Gene Ther 2005;5:323-331.

98. Kwon I, Schaffer DV. Designer gene delivery vectors: molecular engineering and evolution of adeno-associated viral vectors for enhanced gene transfer. Pharm Res 2007 Sep 1 [Epub ahead of print].

99. Puskovic V, Wolfe D, Wechuck J, et al. HSV-mediated delivery of erythropoietin restores dopaminergic function in MPTP-treated mice. Mol Ther 2006;14:710-715.

100. Xue YQ, Zhao LR, Guo WP, Duan WM. Intrastriatal administration of erythropoietin protects dopaminergic neurons and improves neurobehavioral outcome in a rat model of Parkinson's disease. Neuroscience 2007;146:1245-1258.

101. Reglodi D, Tamás A, Lubics A, Szalontay L, Lengvári I. Morphological and functional effects of PACAP in 6-hydroxydopamine-induced lesion of the substantia nigra in rats. Regul Pept 2004;123:85-94.

102. Akerud P, Holm PC, Castelo-Branco G, Sousa K, Rodriguez FJ, Arenas E. Persephin-overexpressing neural stem cells regulate the function of nigral dopaminergic neurons and prevent their degeneration in a model of Parkinson's disease. Mol Cell Neurosci 2002;21:205-222.

103. Krishnamurthi R, Stott S, Maingay M, et al. N-terminal tripeptide of IGF-1 improves functional deficits after 6-OHDA lesion in rats. Neuroreport 2004;15:1601-1604.

104. Shults CW, Ray J, Tsuboi K, Gage FH. Fibroblast growth factor2-producing fibroblasts protect the nigrostriatal dopaminergic system from 6-hydroxydopamine. Brain Res 2000;883:192-204. 